\title{
LANGUAGE AND CATEGORIZATION IN MONOLINGUALS AND BILINGUALS
}

by

Sarah Fairchild

A thesis submitted to the Faculty of the University of Delaware in partial fulfillment of the requirements for the degree of Master of Arts in Psychology

Spring 2017

(C) 2017 Sarah Fairchild

All Rights Reserved 


\title{
LANGUAGE AND CATEGORIZATION IN MONOLINGUALS AND BILINGUALS
}

\author{
by
}

Sarah Fairchild

Approved:

Anna Papafragou, Ph.D.

Professor in charge of thesis on behalf of the Advisory Committee

Approved:

Robert F. Simons, Ph.D.

Chair of the Department of Psychological and Brain Sciences

Approved:

George Watson, Ph.D.

Dean of the College of Arts and Sciences

Approved:

Ann L. Ardis, Ph.D.

Senior Vice Provost for Graduate and Professional Education 


\section{ACKNOWLEDGMENTS}

I would first like to thank my thesis advisor, Professor Anna Papafragou, for all of her help and guidance over the past three years. She has provided encouragement and support for numerous projects, including this one, all while challenging me to think deeper and grow as a scientist. Additionally, I thank the Cognitive faculty for their valuable input on my work throughout the years.

Many thanks are also due to my dad, Paul Fairchild, and my friends and loved ones, all of whom have been more than understanding and supportive throughout my graduate studies. In particular, I would like to thank my fellow graduate students Steve Beighley and Lee Rogers for being the best support system I could ask for.

Finally, special thanks are owed to my undergraduate advisor, Professor Janet van Hell, who sparked my interest in language science and is always there when I need advice on life or science. Without her generosity and caring nature, I would not be here today. 


\section{TABLE OF CONTENTS}

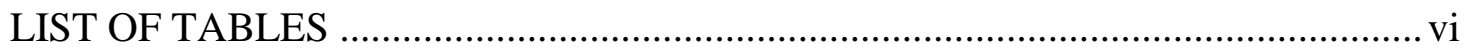

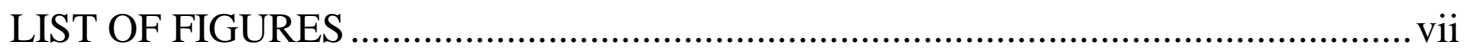

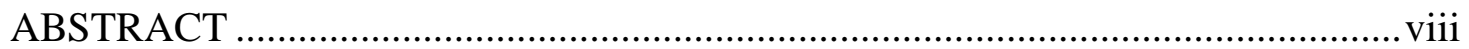

Chapter

1 THE INTERFACE BETWEEN LANGUAGE AND COGNITION ................... 1

1.1 Theoretical Perspectives on Language and Cognition ............................. 2

1.2 Proposal ........................................................................................ 4

2 LINGUISTIC LABELS AND CATEGORIZATION .......................................

2.1 Labels and Categorization Across the Lifespan ......................................... 5

2.2 Individual Differences and Bilingualism.................................................. 6

3 EXPERIMENT: LABELS AND CATEGORIZATION IN MONOLINGUALS AND BILINGUALS ……………….......................... 10

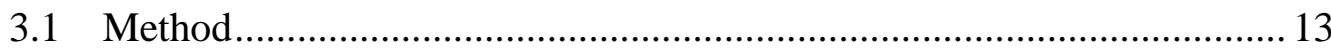

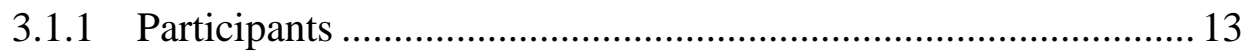

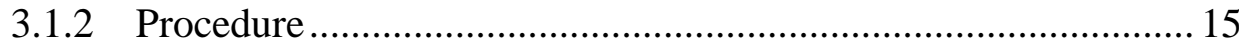

3.1.2.1 Categorization Task ....................................................... 15

3.1.2.2 Linguistic Measure (Lexical Decision Task) ................ 19

3.1.2.3 Cognitive Measures ...................................................... 19

3.1.2.3.1 Digit Span Task .......................................... 19

3.1.2.3.2 Wisconsin Card Sorting Task ...................... 20

3.1.2.3.3 Flanker Task ..............................................2

3.1.2.3.4 Corsi Block-Tapping Task .......................... 21

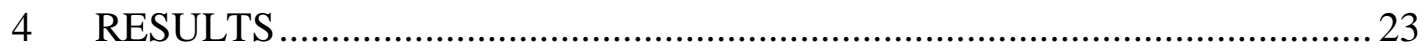

4.1 Categorization Task (Monolingual Group) ………….............................2 23

4.2 Categorization Task (Bilingual Group) …………................................... 25 
4.3 Bilingualism, Linguistic and Cognitive Measures and Individual

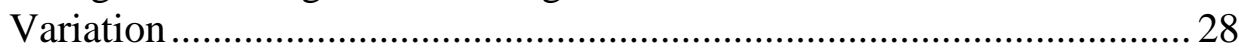

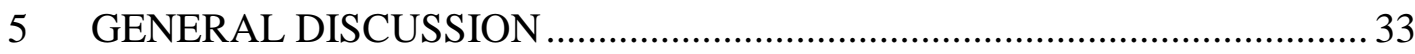

5.1 Language and Categories in Monolinguals and Bilinguals ....................... 33

5.2 Language, Cognition, and Individual Variation in Categorization ...........36

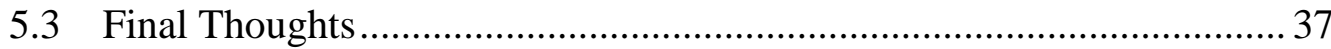

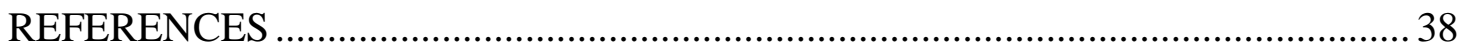

Appendix

INSTITUTIONAL REVIEW BOARD APPROVAL................................................ 46 


\section{LIST OF TABLES}

Table 3.1: Means and standard deviations (in italics) of participant characteristics.... 14

Table 4.1: Means and standard deviations for individual differences measures.

$*_{p}<.05 * *_{p}<.01$, comparison between groups.................................. 29

Table 4.2: Multiple regression analyses predicting Cue Impact in the Categorization

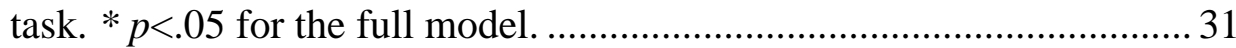




\section{LIST OF FIGURES}

Figure 3.1: Example stimuli. Percentages reflect target similarity to Standard A...... 16

Figure 3.2: Example stimuli for (a) Licit Word, (b) Illicit Word, (c) Frame, and (d) No Cue blocks. .................................................................................... 18

Figure 4.1: Cue compliance for monolinguals in the Categorization task. Error bars represent +/- 1 S.E.M. .................................................................... 25

Figure 4.2: Cue compliance for bilinguals in the Categorization task. Error bars represent +/- 1 S.E.M. 


\begin{abstract}
People tend to treat like-labeled objects as belonging to the same category. An open question is whether the use of labels in categorization varies across individuals due to differences in language experience, linguistic abilities, and/or cognitive abilities. We address this gap by comparing monolinguals' and bilinguals' use of (phonologically) Licit Words (zeg), Illicit Words ( $g s z$ ) and non-linguistic cues (Frames) in forming novel categories. I show that language is unique: Licit Words drove categorization more strongly than Frames. We also observed flexibility: bilinguals made use of both Licit and Illicit Words, presumably because of their willingness to consider novel phonological forms as labels. Across both groups, there was individual variation: linguistic abilities significantly predicted Licit Word use. Thus, language acts as a unique category marker for adults, but the way it is used as a tool for categorization varies systematically as a function of language background and language processing skills.
\end{abstract}




\section{Chapter 1}

\section{THE INTERFACE BETWEEN LANGUAGE AND COGNITION}

How do we experience the world around us? At any given moment, there is an incredibly rich stream of information (visual, auditory, tactile, etc.) available to be processed. In order to function efficiently without becoming perceptually overwhelmed, we as humans have evolved mechanisms to simplify and organize incoming stimuli. We develop perceptual biases (e.g., Werker \& Tees, 1984; Goldstone, 1998; Kelly et al., 2007), form categories (e.g., Bruner, 1957; Rosch \& Mervis, 1975; Mandler \& McDonogh, 1993), and are restricted to focusing our attention on a limited number of items at a time (e.g., James, 1890; Posner, 1980; Desimone \& Duncan, 1995). It has even been argued that our entire perceptual system has evolved such that we interact with a simplification of objective reality (Hoffman, Singh, \& Prakash, 2015). Additionally, we use the uniquely human ability of language to communicate about and categorize elements of the world (e.g., Talmy, 1985;

Aikhenvald, 2004; Cook, Kay, \& Regier, 2005; Majid, Boster, \& Bowerman, 2008).

For example, an infinite number of colors exist on the visible portion of the electromagnetic spectrum, but as English speakers we commonly refer to seven basic colors. Because these are somewhat arbitrary demarcations of a continuous spectrum, languages differ in how many divisions they encode. In contrast to speakers of English, speakers of Berinmo (a language spoken in Papua New Guinea) have five color terms (Davidoff, Davies, \& Roberson, 1999). 
Because of the pervasive nature of language in our everyday life and its powerful ability to carve up the world around us, philosophers and scientists have long been interested in how linguistic and non-linguistic systems interact, and the extent to which arbitrary linguistic categories can affect our experience of the world. Does language affect the way we perceive or think about the world? In what ways to language and cognition interact (if at all)?

\subsection{Theoretical Perspectives on Language and Cognition}

Deterministic views argue that language is equal to cognition or that languages determines perception/cognition. Benjamin Lee Whorf (1956) famously wrote that "We dissect nature along lines laid down by our native language. Language is not simply a reporting device for experience but a defining framework for it." However, strong proposals of this sort have received little empirical support, and are not considered further here. At the other extreme, though, it is clear that language does not act as an entirely modular system (e.g., Fodor, 1986), and instead receives input from and influences other cognitive systems. Cognitive psychologists have thus adopted more nuanced views of how linguistic and non-linguistic information is integrated, however there are differing views of the strength of the influence of top-down linguistic knowledge on bottom-up perception, and how tightly linguistic and nonlinguistic representation are linked in the human mind. These theoretical perspectives can be dichotomized into Relativist and Universalist positions.

Under a Relativist hypothesis, the language that one speaks affects cognitive processes and/or conceptual representations of the world. For example, Relativists would argue that speakers of a language that does not possess an exact number system, like the Amazonian Piraha tribe, are not capable of conceptualizing or working with 
large exact quantities (Gordon, 2004; Frank, Everett, Fedorenko, \& Gibson, 2008).

There are several different formulations of the linguistic relativity hypothesis, but all are based on the idea that the way languages encode information affects non-linguistic cognition. For example, habitual use of the structures and lexicon of a particular language might alter perception (Thierry et al., 2009) or underlying concepts (Boroditsky, Schmidt, \& Phillips, 2003; Gordon, 2004; Pyers \& Senghas, 2009). The Label-Feedback Hypothesis argues that active linguistic representations boost perception in the moment (Lupyan, 2012). Still other formulations argue that language does not fundamentally change non-linguistic cognition, but can serve to improve performance on a variety of cognitive tasks (Waxman \& Markow, 1995; Dehaene et al., 1999; Loewenstein \& Gentner, 2005; Dessalegn \& Landau, 2013). In short, the Relativist position is the language and cognition are tightly linked, and that there is a causal flow from language to thought.

Universalist hypotheses recognize that languages vary cross-linguistically, but argue that conceptual representations remain intact across speakers despite surface variation. We use language to organize and communicate about pre-existing universal non-linguistic concepts (Pinker, 1995). For example, in the domain of color perception, Berlin and Kay (1969) and others (e.g., Kay \& Regier, 2003; Regier, Kay, \& Cook, 2005) have posited that all humans have the same experience perceiving color (taking into account individual variation) and that there are eleven basic color categories. Languages differ in the number of color terms used to describe these color categories in a highly predictable manner. Languages with two color terms make a distinction between black and white (or light and dark), languages with three color terms distinguish black, white, and red, and so on. In sum, the Universalist position is 
that language does not reflect or affect the contents of the mind, but rather is primarily a communication tool that happens to vary in the way information is encoded grammatically and lexically.

The Relativist-Universalist debate is not resolved, partially due to the complex nature of the problem. Recent work has focused on more nuanced proposals, such as the aforementioned theory that language can serve as a cognitive "tool" to aid in complex tasks such as categorization and exact numerical cognition (Waxman \& Markow, 1995; Dehaene et al., 1999; Loewenstein \& Gentner, 2005; Dessalegn \& Landau, 2013). This theory does not posit such tasks are impossible without language, simply that language is one of potentially many tools that can facilitate difficult cognitive processes.

\subsection{Proposal}

In the present work, I investigate the nuanced relationship between linguistic and non-linguistic cognition in the domain of categorization, drawing on previous work that indicates that language, in the form of verbal labels, can act as a tool to facilitate category formation. In Chapter 2, I provide an overview of previous research with children and adults showing that when two objects share a name, or label, individuals are more likely to believe that they belong to the same category. In Chapters 3 and 4, I build on this work with a new experiment aimed to demonstrate that language is a unique tool for categorization in adults. The experiment also investigates the roles of bilingual language experience and individual variation in cognitive and linguistic abilities in mediating the relationship between language and categorization, potentially important factors that have not previously been tested. 


\section{Chapter 2}

\section{LINGUISTIC LABELS AND CATEGORIZATION}

The ability to group entities into categories is one of the key cognitive abilities that enables humans to navigate an extremely complex world. As adults, we integrate multiple dimensions of any given entity in the nuanced process of deciding how it should be categorized. It is widely recognized that language affects this process of categorization in concert with other perceptual and conceptual information. For instance, people are more likely to believe that two objects belong together when they share a label as compared to when no labels are present (Yamauchi \& Markman, 2000; Sloutsky, Lo, \& Fisher, 2001; Lupyan, Rakison \& McClelland, 2007; Johanson \& Papafragou, 2016; Gervits, Johanson \& Papafragou, 2016). In one study, Lupyan et al. (2007) showed that participants learned a labeled category of 'aliens' faster than an unlabeled category, regardless of whether the label was introduced visually or auditorily. Likewise, participants were more likely to group a novel entity with a likelabeled novel object than with a differently-labeled but equally perceptually similar object (Johanson \& Papafragou, 2016). In this way, adults can use language as an “augmenter," or tool to form categories of novel entities (Wolff \& Holmes, 2011).

\subsection{Labels and Categorization Across the Lifespan}

The influence of language on category formation begins well before adulthood, with linguistic labels acting as "invitations to form categories" for infants and children (Jones, Smith, \& Landau, 1991; Waxman \& Markow, 1995; Balaban \& Waxman, 
1997; Waxman, 1999; Nazzi \& Gopnik, 2001; Booth \& Waxman, 2002b; Oakes \& Rakison, 2003; Gershkoff-Stowe \& Smith, 2004; Welder \& Graham, 2006; Fulkerson \& Waxman, 2007; Plunkett, Hu, \& Cohen, 2008; Ferry, Hespos, \& Waxman, 2010). For instance, compared to infants in a no-label control condition, 12-13-month-old infants more effectively formed a category of cars when the label "car" was introduced alongside a toy automobile (Waxman \& Markow, 1995). Similar results have been obtained with unfamiliar objects, with novel labels effectively encouraging 18-montholds to form new categories (Booth \& Waxman, 2002b). For both adults and children, language seems to be a unique path to categories: for instance, words activate existing concepts more efficiently than associative cues do in adults (Boutonnet \& Lupyan, 2015; Lupyan \& Thompson-Schill, 2012) and have an advantage over tones (Ferry et al., 2010), content-filtered speech (Balaban \& Waxman, 1997), and primate vocalizations (Ferry et al., 2013) in facilitating categorization in infants. The precise mechanisms producing these effects are still a matter of debate (see Gelman \& Markman, 1986; Jones, Smith, Landau, 1991; Sloutsky et al., 2001; Sloutsky et al., 2007; Gelman \& Davidson, 2013).

\subsection{Individual Differences and Bilingualism}

An important question left open in the literature is whether the effects of labels on categorization might depend on characteristics of individual cognitive agents. Some studies have noted that adults' reliance on labels during categorization is variable (Sloutsky \& Fisher, 2012), but the underlying reasons for this variability have been left unexplored. One major open possibility is that the effects of language are malleable through experience, specifically bilingual language experience. Monolinguals and bilinguals differ in many respects in the way they acquire and use 
language (e.g., Grosjean, 1989). Bilingual children acquiring two languages simultaneously may be slower to acquire vocabulary in both languages (Bialystok, Luk, Peets, \& Yang, 2010) and less likely to use the mutual exclusivity constraint in acquiring new words (i.e., they are less strict in adhering to a one object-one name rule; Davidson et al., 1997). However, bilingual children develop metalinguistic awareness (Bialystok \& Barac, 2012) and executive function (e.g., Bialystok, 1999) more quickly than monolingual children. In adulthood, bilinguals differ from monolinguals in the way they comprehend and produce speech in both their first (e.g., Van Hell \& Dijkstra, 2002) and second (e.g., Hahne \& Friederici, 2001; Kroll, Bobb, Misra, \& Guo, 2008) languages. The two groups further differ in the way they connect labels to referents (Ameel, Storms, Malt, \& Sloman, 2005; Pavlenko \& Malt, 2011). Most relevant for present purposes, experience with multiple languages has been associated with improved learning of form-meaning links for words (Bartolotti \& Marian, 2012; Cenoz \& Valencia, 1994; Sanz, 2000; Cenoz, 2003; Keshavarz \& Astaneh, 2004; van Hell \& Mahn, 1997); bilinguals have an advantage over monolinguals even when learning novel words with unfamiliar phonological properties (Kaushanskaya \& Marian, 2009) or Morse code languages (Bartolotti, Marian, Schroeder \& Shook, 2011). Because of their unique experience with language, bilinguals may be influenced by words or word-like stimuli to a greater extent than monolinguals when forming new categories. No such difference should be present in the way monolinguals and bilinguals make use of non-linguistic cues to form categories. Moreover, within the group of bilinguals, the use of words to affect categorization might differ depending on age of acquisition, length of exposure and/or degree of proficiency in the second language (see Athanasopoulos et al., 2010). 
Further factors might bear on the use of language to encourage category formation for both monolinguals and bilinguals. One possible source of variation is individual differences in language processing (e.g., Daneman \& Carpenter, 1980; King \& Just, 1991; Tanner, Inoue, \& Osterhout, 2013; Tanner \& Van Hell, 2014). We know that infants and children with larger vocabularies are more likely to categorize objects on the basis of a shared label than their less linguistically-skilled peers (Waxman \& Markow, 1995; Nazzi \& Gopnik, 2001; Ferguson, Havy, \& Waxman, 2015). It is likely that the relationship between verbal skills and use of language in categorization extends into adulthood.

An additional possible source of individual differences in the use of language in categorization is variation in cognitive abilities (e.g., Kane \& Engle, 2002; Carlson, Moses, \& Claxton, 2004; Friedman et al., 2008; Miyake \& Friedman, 2012). When forming novel categories, adults must simultaneously take into account multiple dimensions of the entities at hand, including various perceptual, conceptual, and linguistic features, and inhibit irrelevant dimensions in order to make quick categorization decisions, drawing on our limited-capacity executive function (EF) system. In fact, categorization tasks are often used as measures of executive function (e.g., Bialystok, Barac, Blaye, \& Poulin-Dubois, 2010). Additionally, EF is recruited in learning words (de Abreu, Gathercole, \& Martin, 2011) which are then applied to objects and categories. Thus it seems reasonable to expect that individuals with better EF should be able to more efficiently use linguistic information to form new categories. EF is made up of several subcomponents (verbal working memory, spatial working memory, inhibitory control, and cognitive flexibility) which may individually support the relationship between language and categorization to varying degrees. 
However, currently, the precise role that cognitive abilities play in the use of language in categorization remains underspecified. 


\section{Chapter 3}

\section{EXPERIMENT: LABELS AND CATEGORIZATION IN MONOLINGUALS AND BILINGUALS}

In the present study, I address these open questions by investigating how English-speaking monolingual and early Spanish-English and late English-Spanish bilingual adults use language (and other cues) to form new categories. I focus on the domain of artifacts because this domain has been argued to be more susceptible to categorization by external cues (such as labels) than natural kinds, which tend to be categorized on the basis of "essences" (e.g., Rhodes \& Gelman, 2009; Diesendruck \& Peretz, 2013; Gelman, 2013). I explore whether language has a unique role in shaping novel artifact categories in both monolingual and bilingual adults. Additionally, I ask whether the role of language and other cues in categorization is malleable due to bilingualism or other linguistic and cognitive characteristics of individual cognizers.

I adapt a classic triad task that has been used extensively in the developmental literature to study categorization (Gelman \& Markman, 1986, 1987; Landau \& Shipley, 2001; Gelman \& Coley, 1990; Davidson \& Gelman, 1990; Gelman \& O’Reilly, 1988; Sloutsky et al., 2001; Deng \& Sloutsky, 2012; Gelman \& Davidson, 2013). In this task, participants are presented with three novel objects and have to group one object (Target) with one of the two remaining objects (Standards). Critically, the Target shares a label with one of the Standards, but the shared label does not always align with the degree of perceptual similarity between the Target and each of the Standards. This paradigm offers a strong test of the potency of language on 
category formation: prior developmental work has shown that the degree to which children follow labels to draw category boundaries flexibly integrates considerations of perceptual support. Here I make three important modifications to this basic paradigm. First, I vary the type of cue that is used to group together the Target and one of the Standards. I compare (a) novel, phonologically Licit words (e.g., zeg) that could serve as labels for the unfamiliar artifacts, (b) novel words that are phonologically Illicit in English (e.g., gxz), (c) non-linguistic cues (patterned Frames that surround each object), (d) No Cues. Second, I equate all cue types for discriminability, such that any advantage of one particular cue is unlikely to be explained by lower-level differences. Third, I present all cue types neutrally on the display next to the artifacts (e.g., we do not introduce labels ostensively as names for the objects). Thus any difference among the cues cannot be attributed to differences in intentionality.

If labels have a unique ability to encourage category formation, both monolingual and bilingual participants should be more likely to group together objects when they share a Licit Word as compared to when they share an Illicit Word or Frame, or when no additional information is present (No Cue condition). Furthermore, these effects should be particularly striking when the exemplars are sufficiently perceptually dissimilar to each other and thus would not otherwise be grouped together (cf. Gelman \& Davidson, 2013; Sloutsky et al., 2001). Alternatively, if bilingual language experience leads to a general increase in the willingness or ability to use language in non-linguistic tasks, bilingual adults should be more likely than monolingual adults to rely on Licit Words to categorize. Furthermore, this difference might extend to Illicit Words, since bilinguals learn phonologically novel words more easily than monolinguals (Kaushanskaya \& Marian, 2009) and might thus be more 
likely to accept phonologically unfamiliar strings as novel names for unfamiliar objects. The use of the non-linguistic Frames should be unaffected by language experience. Within the bilingual group, performance may vary with length of exposure to the second language (English for the early bilinguals and Spanish for the late bilinguals), with late bilinguals patterning more like English monolinguals, and early bilinguals showing increased sensitivity to Licit (and perhaps also Illicit) Words. Alternatively, category formation may vary by second language proficiency (and not length of exposure).

In addition to the triad task, participants complete a language processing measure (a lexical decision task) and several measures of executive function (a digit span task targeting verbal working memory, a Wisconsin Card-Sorting test targeting cognitive flexibility, a Flanker test targeting inhibitory control, and a Corsi blocktapping task targeting visual-spatial working memory). Results from these linguistic and cognitive measures are then related to the use of linguistic and non-linguistic cues in the triad task. Of interest is whether greater linguistic-processing abilities (as measured by the lexical decision task) are associated with increased label-based categorization decisions, and whether specific cognitive abilities are related to the ability to integrate linguistic information in categorization. For example, because the cues disappear before the response screen in the present experiment, verbal working memory might most strongly predict label use in categorization as participants may need to hold the Licit or Illicit Words in working memory before making a response; visuo-spatial working memory should have no such effect (but might be similarly predictive of Frame use). Inhibitory control might predict performance on the categorization task, because making use of any of the cues on perceptually dissimilar 
trials requires inhibition of salient visual information. Similarly, to the extent that cognitive flexibility requires inhibition, it is possible that cognitive flexibility could predict overall cue use. Neither inhibitory control nor cognitive flexibility should be particularly tied to the use of Licit Word labels over Frames, however.

\subsection{Method}

\subsubsection{Participants}

Thirty-two English monolingual adults and thirty-two English-dominant bilingual adults aged 18-21 participated. All participants were undergraduate students at the University of Delaware, and received course credit for their participation. In the bilingual group, there were sixteen Spanish-English bilinguals who learned Spanish as a native language but spoke English in educational and professional contexts (i.e., heritage language speakers). The other sixteen participants in that group were EnglishSpanish bilinguals, who learned English as a native language and Spanish as a second language (L2) later in life (i.e., adult L2 learners). All bilinguals reported English as being their dominant language.

A language history questionnaire was administered in the beginning of the testing session and assessed self-rated English (and Spanish, for bilingual participants) proficiency (from 1-10, 10 being the highest). Groups did not differ in terms of selfrated English proficiency. As might be expected, within the bilingual group, SpanishEnglish bilinguals rated themselves as having significantly higher Spanish proficiency than the English-Spanish bilinguals, $t(30)=3.175, p=.003$. Participant characteristics are presented in Table 3.1. 
The language history questionnaire also assessed participants' socio-economic status (SES). SES was operationalized as the level of the participant's mother's level of education: some high school (1), high school (2), some college (3), college (4), or advanced degree (5). SES is reported in the Results section and is included as a variable in the individual differences analyses, as it is known to affect performance on a range of cognitive and linguistic tasks (e.g., Hoff, 2003; Hackman \& Farah, 2009; Calvo \& Bialystok, 2014).

Table 3.1: Means and standard deviations (in italics) of participant characteristics.

\begin{tabular}{lllll}
\hline \hline $\begin{array}{l}\text { Participant } \\
\text { Type }\end{array}$ & Gender & Age & $\begin{array}{l}\text { Self-Rated } \\
\text { English } \\
\text { Proficiency }\end{array}$ & $\begin{array}{l}\text { Self-Rated } \\
\text { Spanish } \\
\text { Proficiency }\end{array}$ \\
\hline $\begin{array}{l}\text { English } \\
\text { Monolingual }\end{array}$ & 13 Male & 18.53 & 9.49 & -- \\
English-Spanish & 3 Male & 18.94 & 9.84 & 6.84 \\
& 13 Female & 1 & .35 & 2.08 \\
Spanish-English & 6 Male & 19.13 & 9.42 & 8.64 \\
& 10 Female & .96 & 1.1 & .88 \\
& 9 Male & 19.03 & 9.63 & 7.74 \\
Total & 23 Female & .97 & .83 & 1.82 \\
\hline \hline
\end{tabular}




\subsubsection{Procedure}

Participants were tested individually or in pairs in a quiet room after they completed the language history questionnaire. All tasks were administered on a laptop with a 15.4" screen, approximately 24 inches away from the participant. The session lasted approximately one hour. All participants were tested in English. Each task was administered in the order below, with the exception of the linguistic measure that was administered last. The categorization and digit span tasks were presented using the OpenSesame experimental presentation software (Mathôt, Schreij, \& Theeuwes, 2012). The rest of the tasks were drawn from the PEBL experimental software test battery (Mueller \& Piper, 2014).

\subsubsection{Categorization Task}

Thirty-two grayscale photographs of objects chosen to be unfamiliar to participants were used as stimuli. These objects included arcane tools and pieces of other man-made devices. To ensure novelty, participants were asked at the completion of the experiment if they recognized any of the objects. The vast majority of participants could not name any of the stimuli, and responded that the objects appeared to be tools of some kind. Only one participant correctly identified a strawberry huller.

The 32 novel objects were divided into 16 pairs, with one object in the pair designated as Standard A, and the other as Standard B. Each pair was morphed together using the Fantamorph program. For each pair, five morphed pictures were created at $10 \%, 30 \%, 50 \%, 70 \%$, and $90 \%$ similarity to Standard A according to the program (see Figure 3.1 for an example). 


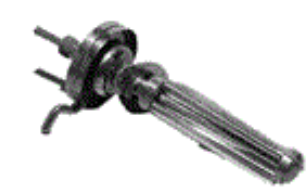

Standard B

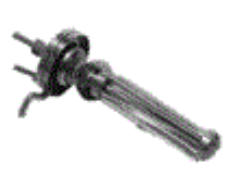

$10 \%$

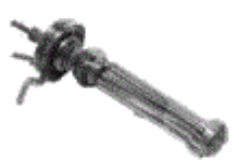

$30 \%$

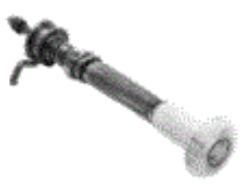

$50 \%$

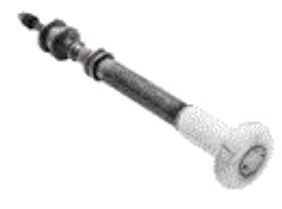

Standard A

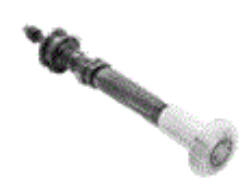

$70 \%$

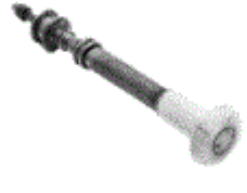

$90 \%$

Target

Figure 3.1: Example stimuli. Percentages reflect target similarity to Standard A.

Eight novel Licit Words were generated using the ARC Nonword Database (Rastle, Harrington, \& Coltheart, 2002) with the following specifications: a length of three to five letters, orthographically existing onsets, orthographically existing bodies, and legal bigrams (e.g., zeg, wob, sten). All labels were also created such that they were also phonologically possible labels in Spanish. Eight novel Illicit Words were also created by taking the reverse of the Licit Words and replacing the vowels with x's. For example, zeg would become gxz. These Illicit Words were phonologically disallowed in English. Finally, eight patterned Frames (e.g., solid, dashed) were created to surround the objects. These served as non-linguistic cues.

Two norming studies were conducted. First, I assessed whether or not people were sensitive to the similarity manipulations in our morphed stimuli. A separate group of 10 monolingual English-speaking adults were presented with all possible Standard/Target triads, and were asked to rate the similarity of the Target to one of the 
Standards on a 9-point scale, $10-90 \%$. Participants were very accurate at rating the $30 \%, 50 \%$, and $70 \%$ morphs; ratings did not differ significantly from actual similarity (all $p$ 's $<.05$ ). Ratings for the $10 \%$ and $90 \%$ stimuli differed significantly from actual similarity, but in the predicted direction. The $10 \%$ objects were rated significantly lower than the $30 \%$ objects, $t(9)=7.003, p<.001$, and the $90 \%$ objects were rated significantly higher than the $70 \%$ objects, $t(9)=10.902, p<.001$. Second, I ensured that all three cue types were equally discriminable. A separate group of 10 monolingual adults from the same population were asked to rate the discriminability of pairs of Licit Words, Illicit Words, and Frames. For each pair, they answered the question 'How similar are these two items?' on a seven-point scale. Ratings did not differ across cue types ( $p$ 's $>.1)$.

For each trial of the categorization task, I combined Standard A and B from one of the 16 novel object pairs, and a Target from that set. The Standards were presented on the top of the screen their placement (left side or right side) counterbalanced, and the Target was centered on the bottom of the screen. The triad remained on the screen for 1000 milliseconds, at which point cues were introduced. There were four within-subjects cue conditions: Licit Words, Illicit Words, Frames, and a No Cue control condition. Cues appeared below the objects for 2000 milliseconds (see Figure 3.2), and the cue for the Target always matched the cue for Standard A. When the cues disappeared, a red frame appeared along the edges of the screen. 


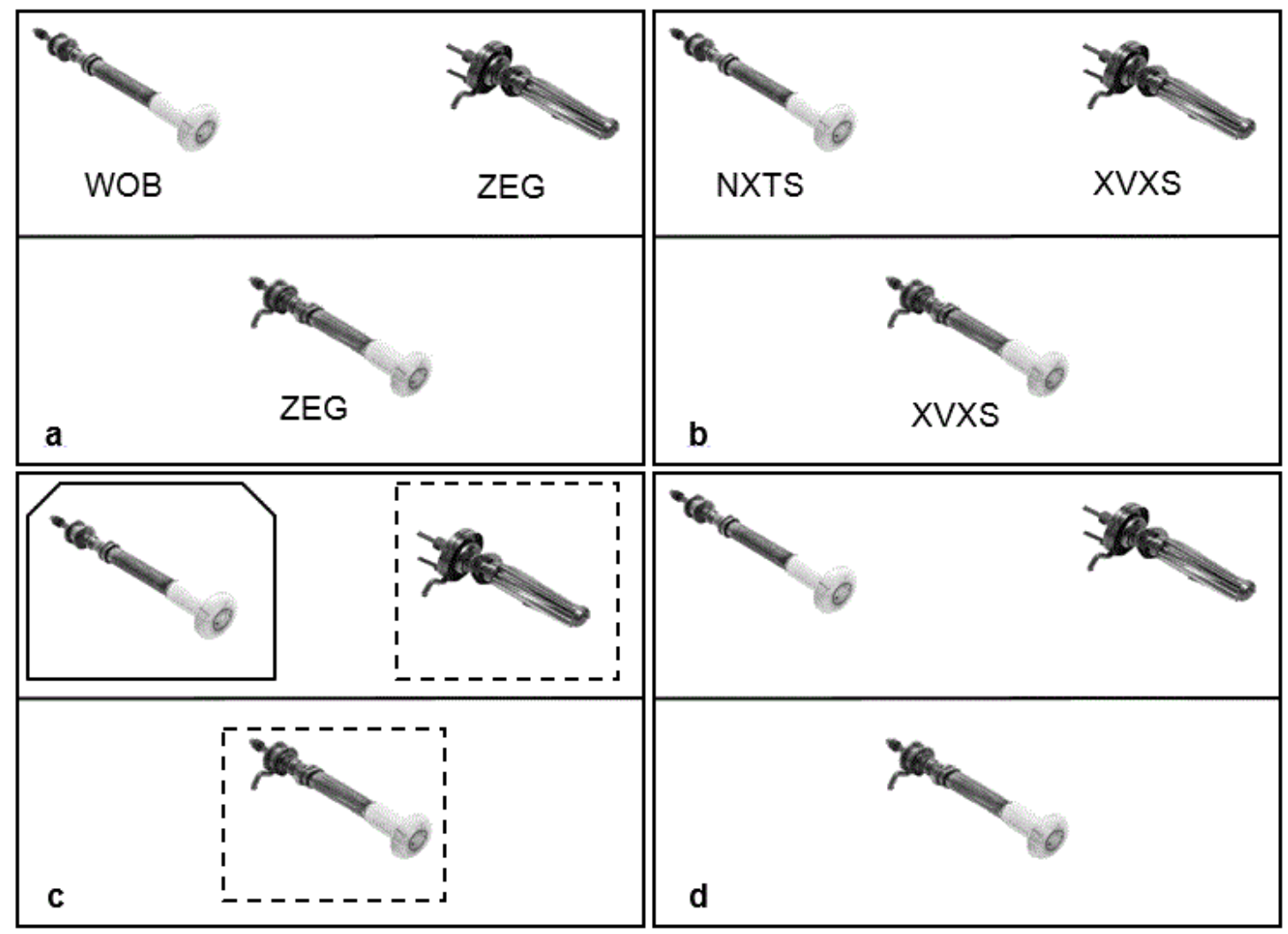

Figure 3.2: Example stimuli for (a) Licit Word, (b) Illicit Word, (c) Frame, and (d) No Cue blocks.

At the beginning of the task participants were given on-screen instructions that were read aloud by the experimenter. They were told that they would see groups of three objects, and that they would be given time to look at the objects. Then, a red frame would appear on the screen. They were told that when the red frame appeared, they should press a key to indicate where they thought the bottom object belonged, either with the object on the right or the object on the left. Participants were instructed to make a response as quickly as possible.

There were four blocks of trials, one for each cue type, with block order counterbalanced across participants. Stimuli were fully rotated across cue types. 
Within each block, participants saw all possible target/standard triads in a random order, 20 trials per block, for a total of 80 trials.

\subsubsection{Linguistic Measure (Lexical Decision Task)}

Participants completed a lexical decision task as a measure of English comprehension ability. This task has been shown to accurately predict language processing skills in various groups of monolinguals and bilinguals (Harrington, 2006). Twenty English words (e.g., EDUCATION) and twenty pseudowords (e.g., EMUCATION) were presented in a random order for 500 milliseconds each. Participants were asked to indicate by keypress, as quickly as possible, whether or not each stimulus was a real English word. Both accuracy and reaction times were collected. For the analysis of reaction times, incorrect responses and responses slower than 3000 milliseconds were excluded.

\subsubsection{Cognitive Measures}

\subsection{Digit Span Task}

Participants completed the digit span task as a measure of verbal working memory. Numbers were presented randomly on the screen, one at a time, and participants were then asked to type the numbers in numerical order from smallest to largest. The advantage of this type of digit span task over a forward or backward digit span is that participants are not only required to hold items in memory, but are also required to actively perform an operation on the number set (re-ordering). Because of this requirement, the re-ordered digit span is thought to more accurately represent verbal working memory than forward or backward digit span tasks that can be completed using short-term memory alone, not working memory (Diamond, 2013). On 
each trial of the task, two to eight single-syllable digits $(1,2,3,4,5,6,8,9)$ were presented for 750 milliseconds each. Participants were then asked to type as many numbers as they could remember, in numerical order from smallest to largest. The recall phase was untimed, and participants could move on to the next trial when ready. All participants completed a total of 10 trials.

\subsection{Wisconsin Card Sorting Task}

A variant of the 64-card Wisconsin Card Sorting task (Kongs et al., 2000) was administered as a measure of cognitive flexibility. Versions of this standard task have been used to measure the ability to shift between mental sets in children (Bull \& Scerif, 2001; Romine et al., 2004), adults (Rhodes, 2004; Buschbaum, Greer, Chang, \& Berman, 2005), and patient populations (Gold et al., 1997; Stuss et al., 2000). Participants were given a deck of 64 cards, one card at a time, and were asked to sort the cards into four piles by clicking on the intended pile. There was no time constraint on responses. The cards could be sorted by color, number, or shape. Participants were not told the rule, but were given feedback (correct/incorrect) after each card they placed, allowing them to learn the rule. The sorting rule changed throughout the task, and participants were informed that if this happened (i.e., they started getting negative feedback), they should attempt to figure out the new rule as soon as possible. The rule changed up to four times over the course of the task. I calculated a measure of cognitive flexibility by taking the average number of trials it took participants to learn each new rule. 


\subsection{Flanker Task}

The Flanker task is a widely used measure of inhibitory control (Eriksen \& Eriksen, 1974) with high test-retest reliability (Wöstmann et al., 2013). Participants responded to the direction of an arrow in the center of the screen, either left or right, by pressing a key as quickly as possible. The critical manipulation is the direction of other arrows surrounding the center arrow. On incongruent trials, the arrow was flanked by arrows facing the opposite direction $(<<><<)$. On congruent trials, all of the arrows faced the same direction $(\ll<<<)$. On neutral trials, the center arrow was flanked by dashes (--<--). Single trials were also included, in which the arrow was presented in isolation (>). Inhibitory control is recruited to a greater extent for incongruent trials, which require participants to ignore the direction of distractor stimuli and respond only to the center arrow. Participants completed a total of 48 trials (12 per condition), preceded by 16 practice trials that included feedback (correct/incorrect). Trials timed out after 800 milliseconds if no response was detected. A measure of Flanker Conflict was calculated as the difference in reaction times between incongruent and congruent trials. Thus, participants with less Flanker Conflict had better inhibitory control.

\subsection{Corsi Block-Tapping Task}

The Corsi block-tapping task was given as a measure of visual-spatial working memory (Kessels et al., 2000). This task is used as a standard measure of visual-spatial working memory in much experimental research (Fischer, 2001), and plays an important role in clinical diagnoses of diseases such as Alzheimer's (Carlesimo et al., 1994), Parkinson's (Stoffers et al., 2003), and schizophrenia (Chey et al., 2002). On each trial of the task, an array of blue squares was presented on the screen, and then 
three to eight squares briefly sequentially changed color for 250 milliseconds each. Participants were asked to repeat what they had seen by clicking on the squares that changed color, in the order that they did so. There was no time constraint for responses. The task increased in difficulty on each trial and ended when the participant incorrectly answered three trials in a row. A measure of working memory span, the highest number squares accurately recalled (Cowan's k), was calculated for each participant. 


\section{Chapter 4}

\section{RESULTS}

\subsection{Categorization Task (Monolingual Group)}

A 4 (Cue Type: Licit Word, Illicit Word, Frame, No Cue) by 5 (Perceptual Similarity: $10 \%, 30 \%, 50 \%, 70 \%, 90 \%$ ) repeated-measures ANOVA was performed with Cue Compliance as the dependent variable. I considered Cue-Compliant responses to be those where the participant categorized the target object with the cuematched Standard A. Cue Compliance in the No Cue block was calculated in the same way (i.e., in terms of responses to the predetermined Standard A).

The ANOVA yielded a significant main effect of Cue Type, $F(3,93)=9.498$, $p<.001, \eta^{2}=.063$. Post-hoc tests (Bonferroni corrected) indicated that there was significantly greater Cue Compliance in the Licit Word condition $(M=.66, S D=.12)$ as compared to the Illicit Word $(M=.58, S D=.10), p<.001$, Frame $(M=.57, S D=$ $.11), p<.001$, and No Cue conditions $(M=.54, S D=.06), p<.001$. There were no significant differences across the Illicit Word, Frame, and No Cue conditions (all p's > .1). There was also a main effect of Perceptual Similarity, $F(2.44,75.64)=709.086, p$ $<.001, \eta^{2}=.823$. As expected, Cue Compliance increased as Perceptual Similarity grew (all p’s <.05).

There was also a significant interaction between Cue Type and Perceptual Similarity, $F(6.14,190.46)=2.911, p=.001, \eta^{2}=.043$. Post-hoc tests (Bonferroni corrected for multiple comparisons) revealed that for the $10 \%$ similar trials, there was higher Cue Compliance in the Licit Word block as compared to the Illicit Word, $p=$ 
.045 , Frame, $p=.005$, and No Cue blocks, $p=.003$ (these three conditions did not differ from one another). For 30\% similar trials, there was higher Cue Compliance for Licit Words as compared to Illicit Words, $p=.008$, Frames, $p=.003$, and the No Cue control, $p<.001$; there was also higher Cue Compliance for Illicit Words as compared to the No Cue condition, $p=.021$ and no other significant differences. For $50 \%$ similar trials, in which the Target was perceptually ambiguous with respect to the two Standards, Cue Compliance did not differ significantly across Licit Word, Illicit Word and Frame blocks, $p$ 's $>.05$; of these three conditions, only the Licit Word condition led to higher Cue Compliance than the No Cue condition, $p<.001$ (other $p$ 's $>.1$ ). Cue Compliance did not vary across conditions for $70 \%$ and $90 \%$ similar trials. Thus, there was an advantage for Licit Words over all other cues for $10 \%$ and $30 \%$ perceptually similar trials, and an advantage of Licit Words over the No Cue control condition for the perceptually ambiguous $50 \%$ similarity condition. When the objects were very similar (70\% and 90\% conditions), Cue Compliance was already at ceiling and therefore the cues did not alter responses above and beyond perceptual similarity. Results are shown in Figure 4.1. 


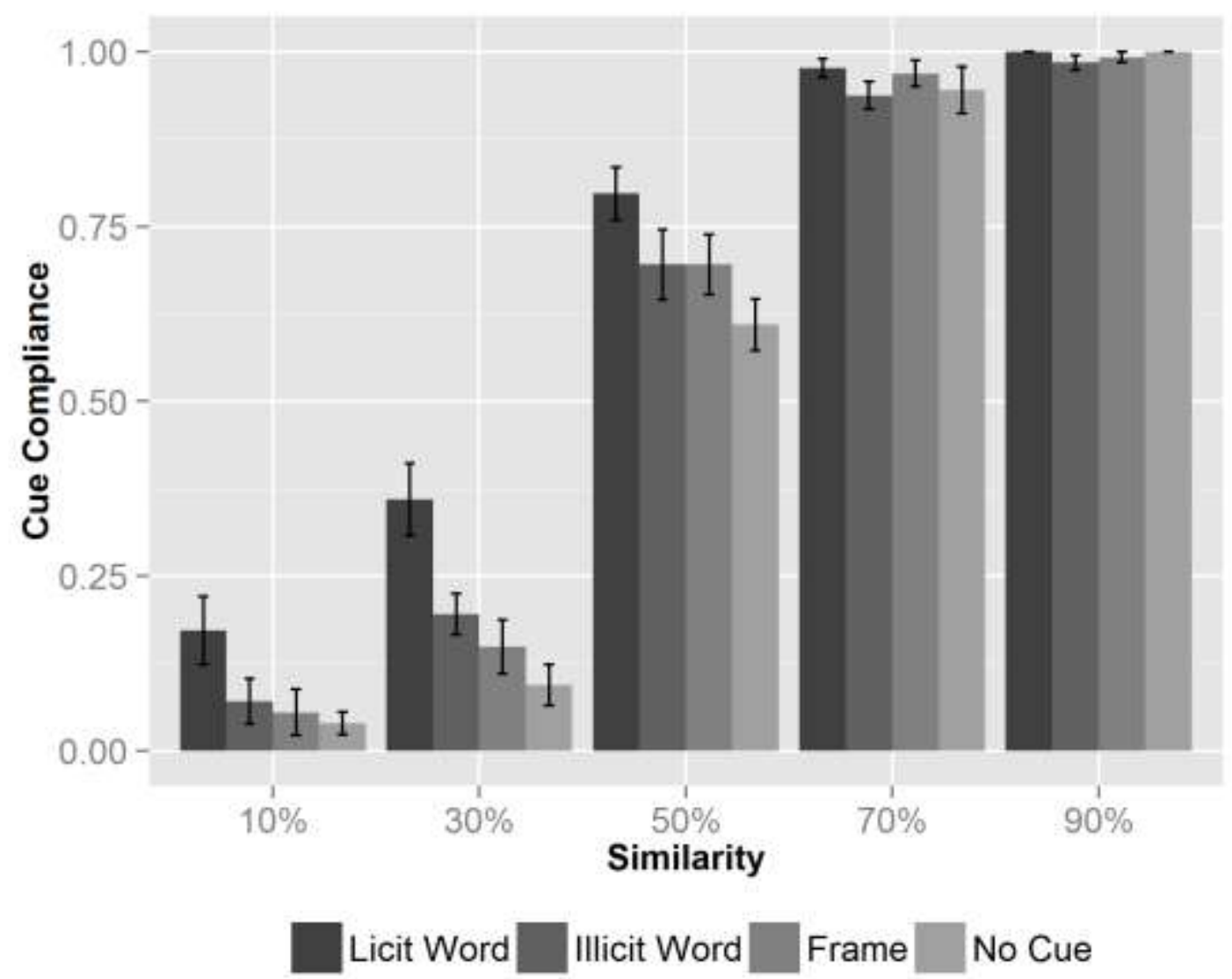

Figure 4.1: Cue compliance for monolinguals in the Categorization task. Error bars represent +/- 1 S.E.M.

\subsection{Categorization Task (Bilingual Group)}

A 4 (Cue Type: Licit Word, Illicit Word, Frame, No Cue) by 5 (Perceptual Similarity: 10\%, 30\%, 50\%, 70\%, 90\%) repeated-measures ANOVA with Bilingual Type (Spanish-English, English-Spanish) as a between-subjects factor was performed on the proportion of Cue-Compliant responses made by the bilingual participants. This analysis revealed a significant main effect of Cue Type, $F(3,90)=11.783, p<.001, \eta^{2}$ $=.081$. As in the monolingual group, there was greater Cue Compliance in the Licit 
Word condition $(M=.70, S D=.38)$ as compared to the Frame $(M=.57, S D=.43), p$ $<.001$, and No Cue $(M=.55, S D=.44)$ conditions, $p<.001$ (the Frame and No Cue conditions did not differ, $p>$.1.) Unlike the monolingual group, however, the Licit Word condition did not differ from the Illicit Word $(M=.65, S D=.40)$ condition, $p>$ .1 ; furthermore, there was greater Cue Compliance in the Illicit Word condition as compared to the Frame, $p=.003$, and No Cue conditions, $p<.001$.

There was also a significant main effect of Perceptual Similarity, $F(2.4,72)=$ 409.207, $p<.001, \eta^{2}=.743$. Cue Compliance increased with each level of Perceptual Similarity (all $p$ 's $<.001$ ) except for the $70 \%$ and $90 \%$ conditions, $p>.1$. There was no significant main effect of Bilingual Type, nor were there significant interactions between Bilingual Type and Cue Type or Bilingual Type and Similarity (all $p$ 's $>.1$ ).

The interaction between Cue Type and Perceptual Similarity was also significant, $F(6.6,198)=5.346, p<.001, \eta^{2}=.069$. Post-hoc tests (Bonferroni corrected) indicated that for $10 \%$ similar trials, there was higher Cue Compliance in the Licit Word condition as compared to the Frame, $p<.001$, and No Cue conditions, $p<.001$; Cue Compliance was also higher for the Illicit Word than for the Frame, $p=$ .020 , and the No Cue conditions, $p=.002$ (no other differences were significant). On $30 \%$ similar trials, there was significantly greater Cue Compliance in the Licit Word condition as compared to the Frame, $p=.006$, and No Cue conditions, $p<.001$, which did not differ from one another, $p>.1$. There was also greater Cue Compliance for the Illicit Word as compared to the Frame, $p=.020$, and No Cue conditions, $p=.008$. Licit Words and Illicit Words did not differ from one another, $p>$.1. For 50\% similar (ambiguous) trials, there was again greater Cue Compliance for Licit Words than for Frames, $p=.008$, and the No Cue control, $p<.001$; the last two conditions did not 
differ, $p>.1$. Illicit Word Cue Compliance was greater than Cue Compliance in the No Cue condition, $p=.003$, but did not differ significantly from Licit Words or Frames, both $p$ 's $>.1$. Cue Compliance did not vary across conditions for $70 \%$ and 90\% similar trials. Therefore, unlike for the monolingual group, I observed an advantage for both Licit and Illicit Words over Frames and the No Cue control in the $10 \%$ and $30 \%$ similarity conditions. Licit and Illicit Word cue compliance did not differ from one another. For the perceptually ambiguous 50\% trials, Licit and Illicit Words had greater cue compliance than the No Cue condition. As with the monolinguals, Cue Compliance was already at ceiling in the $70 \%$ and $90 \%$ conditions. Results (collapsing across the two bilingual groups for simplicity) are presented in Figure 4.2. 


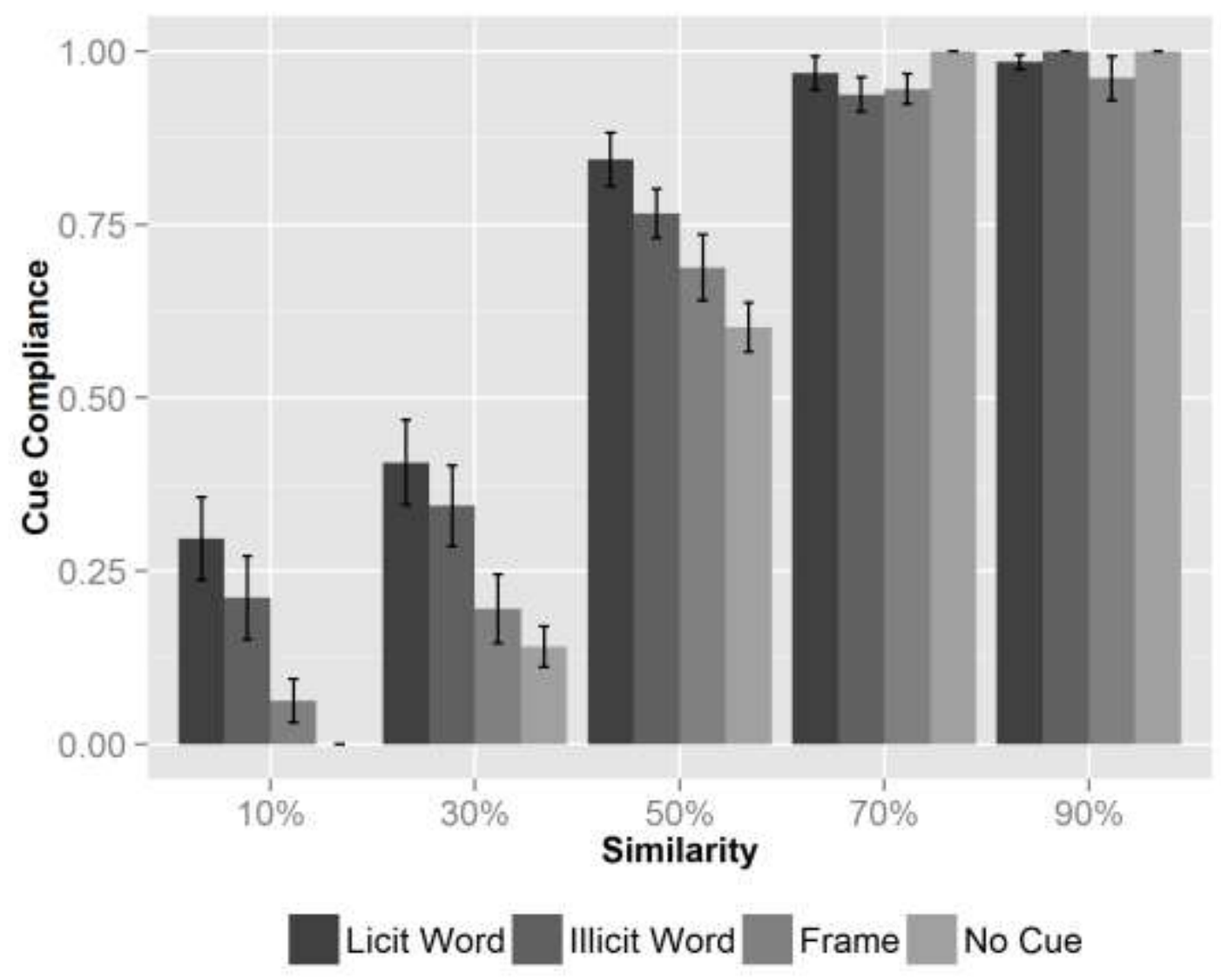

Figure 4.2: Cue compliance for bilinguals in the Categorization task. Error bars represent +/- 1 S.E.M.

\subsection{Bilingualism, Linguistic and Cognitive Measures and Individual Variation}

The analyses so far have not directly targeted the role of bilingual language experience in altering the use of various cues in categorization. Before performing a direct comparison of monolinguals vs. bilinguals, I assessed the individual differences measures for the two groups (see Table 4.1; I collapsed across early and late bilinguals since earlier statistical analyses revealed no difference between them.) As seen in Table 4.1, the two groups were similar, except that bilinguals had significantly lower 
socio-economic status (as indexed by a report of the participant's mother's level of education) than monolinguals, $t(62)=2.962, p=.004$, in addition to significantly lower scores on the cognitive flexibility task, $t(62)=2.071, p=.043$. Therefore, I used multiple regression analyses to investigate the role of bilingual language experience while keeping all other factors (e.g., SES, executive function) constant, thus providing the fairest possible comparison between groups. Similar analyses were used to understand how the linguistic and cognitive measures listed in Table 4.1 might predict the use of linguistic and non-linguistic cues in the categorization task, regardless of monolingual/bilingual status.

Table 4.1: Means and standard deviations for individual differences measures. ${ }^{*} p<.05$ $* * p<.01$, comparison between groups.

\begin{tabular}{llll}
\hline Variable & Monolinguals & Bilinguals & Total \\
\hline $\begin{array}{l}\text { Participant } \\
\text { characteristics }\end{array}$ & & & \\
SES (out of 5) & $3.88(.98)$ & $2.97(1.54)$ & $3.44(1.35)$ \\
& & & \\
$\begin{array}{l}\text { Linguistic measures } \\
\begin{array}{l}\text { English Comprehension } \\
\text { (ACC) }\end{array}\end{array}$ & $.90(.09)$ & $.92(.08)$ & $.91(.08)$ \\
$\begin{array}{l}\text { English Comprehension } \\
\text { (RTs) }\end{array}$ & $673.88(135.71)$ & $665.88(129.20)$ & $665.17(131.83)$
\end{tabular}

Cognitive measures

Verbal Working Memory $(\%)$ 
Cognitive Flexibility (\#

trials)*

$10.21(3.80)$

$12.99(7.00)$

$11.60(5.71)$

Inhibitory Control

(Conflict)

$42.36(42.14) \quad 58.72(39.81) \quad 50.26(41.52)$

Visual-Spatial Working

Memory Span

$5.75(.83)$

$5.67(.90)$

$5.71(.86)$

For these analyses, I calculated measures of Cue Impact, which represented the effectiveness of a particular cue in comparison to the No Cue baseline. For each cue, I collapsed across levels of Perceptual Similarity and subtracted Cue Compliance in the No Cue condition from Cue Compliance in each cue condition to obtain the Cue Impact (e.g., Licit Word compliance - No Cue compliance $=$ Licit Word Impact). I then performed three separate multiple regression analyses, with the Licit Word Impact, the Illicit Word Impact, and the Frame Impact as dependent variables. Data from all participants were included (with the exception of one bilingual who did not complete the battery of individual differences measures). Bilingualism (Monolingual, Bilingual), SES, English Lexical Decision performance (Accuracy and Reaction Times), Verbal Working Memory, Visual-Spatial Working Memory, Inhibitory Control, and Cognitive Flexibility were included in the model as predictors. This model significantly predicted the Licit Word Impact, $F(9,53)=2.231, p=.034, R^{2}=$ .274 , and the Illicit Word Impact, $F(9,53)=2.512, p=.017, R^{2}=.299$, but not the Frame Impact $(p>.1)$. Full results of each analysis are presented in Table 4.2. Closer inspection reveals that English Lexical Decision performance, both in terms of accuracy $(\beta=.386 . t(53)=2.888, p=.006)$ and reaction times $(\beta=-.314 . t(53)=$ $2.289, p=.026$ ), was a significant predictor of the Licit Word Impact. That is, the faster and more accurately participants responded in the Lexical Decision task, the 
more likely they were to use Licit Words to form categories over and above what they would do in the No Cue condition. Bilingualism was the only significant predictor of the Illicit Word Impact $(\beta=.346 . t(53)=2.678, p=.010)$ : bilinguals were significantly more likely than monolinguals to use Illicit Words in the Categorization task.

Table 4.2: Multiple regression analyses predicting Cue Impact in the Categorization task. $* p<.05$ for the full model.

\begin{tabular}{|c|c|c|c|c|c|c|}
\hline \multirow[b]{2}{*}{ Variable } & \multicolumn{2}{|c|}{$\begin{array}{l}\text { Licit Word } \\
\text { Impact }^{\star}\end{array}$} & \multicolumn{2}{|c|}{$\begin{array}{l}\text { Illicit Word } \\
\text { Impact }^{*}\end{array}$} & \multicolumn{2}{|c|}{ Frame Impac } \\
\hline & $\beta$ & $p$ & $\beta$ & $p$ & $\bar{\beta}$ & $P$ \\
\hline \multicolumn{7}{|c|}{ Participant characteristics } \\
\hline Bilingualism & .101 & .444 & .346 & .010 & -.026 & .855 \\
\hline SES & .055 & .673 & .089 & .489 & .203 & 149 \\
\hline
\end{tabular}

Linguistic measures

English Comprehension (ACC)

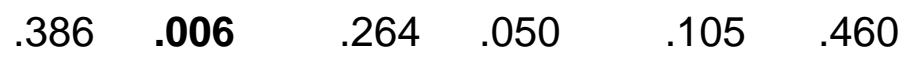

English Comprehension (RTs)

$\begin{array}{llllll}-.314 & .026 & -.046 & .734 & -.127 & .389\end{array}$

Cognitive measures

$\begin{array}{lllllll}\text { Verbal Working Memory } & .107 & .407 & .123 & .336 & -.179 & .197\end{array}$

$\begin{array}{lllllll}\text { Visual-Spatial Working } & -.172 & .164 & -.217 & .077 & .002 & .985\end{array}$

Memory

Inhibitory Control

$\begin{array}{llllll}.097 & .442 & .136 & .272 & .245 & .070\end{array}$


Cognitive Flexibility

$\begin{array}{llllll}-.071 & .574 & -.226 & .074 & -.189 & .164\end{array}$




\section{Chapter 5}

\section{GENERAL DISCUSSION}

A wealth of prior research demonstrates that infants, children, and adults tend to group objects together if these objects share the same linguistic label (e.g., Gelman

\& Markman, 1986; Waxman \& Markow, 1995; Lupyan et al., 2007). This work has noted some variation in how individuals make use of language during categorization (Sloutsky \& Fisher, 2012) but the nature of this variation has not been systematically examined. Here I compared the effects of Novel (phonologically) Licit Words (zeg), Novel Illicit Words ( $g x z)$ and non-linguistic cues (Frames) on the way people form novel artifact categories. I was particularly interested in assessing the contributions of characteristics such as language experience/bilingualism, linguistic skills, and cognitive abilities to the use of these different cue types.

\subsection{Language and Categories in Monolinguals and Bilinguals}

A major finding from the present work is that language is unique: for both monolinguals and bilinguals, Licit Words drove categorization more strongly than non-linguistic Frames, particularly in the absence of perceptually supporting evidence (i.e., for Standard-Target pairs that were only $10 \%$ or $30 \%$ similar to each other) even though Licit Words did not override perceptual similarity (cf. also Gelman \& Markman, 1987; Davidson \& Gelman, 2013; Diesendruck \& Peretz, 2013). These results are in line with previous developmental studies showing a label advantage in forming novel categories (e.g., Fulkerson \& Waxman, 2007), and adult studies 
showing that words are more effective than non-linguistic cues in activating existing categories (e.g., Boutonnet \& Lupyan, 2015). My findings go beyond earlier work by showing that, even for adults, labels help the formation of novel categories more than non-linguistic cues, and this effect surfaces even when labels are equated to nonlinguistic cues in terms of discriminability or intentional presentation. Furthermore, my findings break new ground by showing that this strong relationship between language and categorization is unchanged by the acquisition of a second language. Despite the fact that bilinguals differ in numerous ways from monolinguals in the way they acquire and use language (Grosjean, 1989) and the fact that a bilingual's languages are active at all times (Hermans et al., 1998), being bilingual did not increase the likelihood of using unfamiliar but phonologically well-formed words as an aid to categorization.

Beyond these similarities, my findings also reveal a striking difference between participants with diverse language backgrounds: unlike monolinguals, who only made use of Licit Words to categorize, both phonologically possible Licit Words and phonologically impossible Illicit Words facilitated categorization for bilinguals, and to the same extent. This pattern was not due to bilinguals' lower English proficiency or overall higher cognitive function: controlling for English processing ability (as measured by a lexical decision task) and cognitive abilities (as measured by executive function measures), increased use of Illicit Words was specifically linked to bilingual language experience. Furthermore, it is unlikely that bilinguals' particular experience with Spanish was responsible for the pattern associated with Illicit Words: in Spanish (just like in English), consonant-only strings such as gxz are not phonologically allowed words. Finally, the observed pattern was not linked to age of 
acquisition of a second language: Spanish-English bilinguals who grew up speaking both languages and English-Spanish bilinguals who learned their L2 later in life did not differ in their categorization patterns (both groups had reached a moderately high level of proficiency in their second language).

I propose that individuals with bilingual language experience are likely to use linguistic information more flexibly than monolinguals, treating letter strings that do not correspond to phonologically well-formed words in the languages they know as potential words carrying meaningful information. This finding is entirely consistent with recent evidence that bilinguals have an advantage over monolinguals when learning novel words with unfamiliar phonological properties (Kaushanskaya \& Marian, 2009) or Morse code languages (Bartolotti et al., 2011). It is also consistent with evidence that bilingual children show increased metalinguistic awareness (Bialystok \& Barac, 2012), and adjust their expectations about the meanings of unfamiliar words to accommodate the need to navigate two linguistic systems (e.g., by applying the mutual exclusivity constraint more flexibly than monolingual learners; Davidson et al., 1997). In my own data, bilinguals' increased ability to treat phonologically unfamiliar strings as potential words has consequences for cognitive tasks such as categorization, where such unfamiliar strings are treated as labels (and hence category markers) for novel artifacts.

It remains to be seen whether the enhanced ability to process phonologically impossible strings might influence task performance in studies of cognition considered to be relatively non-linguistic. For example, some classic memory tasks involve the memorization of consonant strings (e.g., Shulman \& Greenberg, 1971; Shuell \& Giglio, 1973). Phonologically impossible consonant strings are also often used in tasks 
of subliminal priming to investigate what kind of information enters conscious awareness and to what level such information is processed (e.g., Dehaene et al., 2003; Boulenger et al., 2008; Vidal et al., 2014). If bilinguals are able to process such strings more efficiently than monolinguals, it is critical for experimenters to consider participants' second language knowledge when interpreting results. However, it is rarely the case in studies of memory or conscious awareness that this variable is taken into consideration.

\subsection{Language, Cognition, and Individual Variation in Categorization}

A major aspect of the present work was to examine the role of individual differences in how language and other cues bear on categorization. I found that, regardless of bilingual language status, variation in dominant language (English) processing skills affected the relationship between language and categorization: individuals with higher English processing skills as measured by a lexical decision task were more likely to be influenced by Licit Words in the categorization task. I also found that variation in executive function capacity did not explain the use of either linguistic or non-linguistic cues in categorization. Given the tight link between executive function and categorization - categorization requires keeping relevant properties in mind and inhibiting irrelevant items, thus categorization tasks are often used as EF measures (e.g., Kongs et al., 2000; Zelazo, 2006) - this last result may appear surprising. It is possible that my categorization task was not sufficiently cognitively demanding and my participant group (young college-aged adults at peak cognitive performance) was not diverse enough for this relationship to emerge.

The finding that individuals with better linguistic skills weigh linguistic information more heavily in category formation meshes nicely with infant data that 
have shown a link between the use of labels in categorization and vocabulary development (Balaban \& Waxman, 1997; Nazzi \& Gopnik, 2001; Ferguson et al., 2015). The direction of this relationship remains an open topic of discussion in the literature. In my present data with adults, there are several possible explanations for the link between language processing ability and label use in categorization. One option is that better linguistic skills caused some of my participants to consider the importance of novel linguistic labels, motivating them to subsequently apply them to objects during the categorization task. Alternatively, these individuals have been simply more efficient in processing the novel labels in both the categorization task and the lexical decision task.

\subsection{Final Thoughts}

Taken together, the present data support the conclusion that language is unique in its ability to influence novel category formation. Both monolingual and bilingual adults spontaneously use labels to form categories, and ignore equally discriminable external non-linguistic cues. Experience with a second language can make individuals more flexible in what they consider a viable label, with implications for categorization. Furthermore, linguistic abilities - but not cognitive abilities contribute to systematic individual variation in the use of language as a tool for categorization. My results suggest that previously reported "diffuse" patterns of compliance with linguistic labels in adults' categorization behavior (e.g., Sloutsky, Kloos, \& Fisher, 2007; Sloutsky \& Fisher, 2012) may stem from systematic individual differences. Thus my findings underscore the importance of considering participant characteristics when investigating the complex relationship between language and cognition. 


\section{REFERENCES}

Ameel, E., Storms, G., Malt, B. C., \& Sloman, S. A. (2005). How bilinguals solve the naming problem. Journal of Memory and Language, 53(1), 60-80.

Athanasopoulos, P., Dering, B., Wiggett, A., Kuipers, J. R., \& Thierry, G. (2010). Perceptual shift in bilingualism: Brain potentials reveal plasticity in preattentive colour perception. Cognition, 116(3), 437-443.

Balaban, M. T., \& Waxman, S. R. (1997). Do words facilitate object categorization in 9-month-old infants? Journal of Experimental Child Psychology, 64, 3-26.

Bartolotti, J., \& Marian, V. (2012). Language learning and control in monolinguals and bilinguals. Cognitive science, 36(6), 1129-1147.

Bialystok, E., \& Barac, R. (2012). Emerging bilingualism: Dissociating advantages for metalinguistic awareness and executive control. Cognition, 122(1), 67-73.

Bialystok, E., Barac, R., Blaye, A., \& Poulin-Dubois, D. (2010). Word mapping and executive functioning in young monolingual and bilingual children. Journal of Cognition and Development, 11(4), 485-508.

Bialystok, E., Luk, G., Peets, K. F., \& Yang, S. (2010). Receptive vocabulary differences in monolingual and bilingual children. Bilingualism: Language and Cognition, 13(4), 525-531.

Booth, A. E., \& Waxman, S. R. (2002b). Object names and object functions serve as cues to categories for infants. Developmental Psychology, 38(6), 948-957.

Boulenger, V., Silber, B. Y., Roy, A. C., Paulignan, Y., Jeannerod, M., \& Nazir, T. A. (2008). Subliminal display of action words interferes with motor planning: a combined EEG and kinematic study. Journal of Physiology-Paris, 102(1), 130136.

Boutonnet, B., \& Lupyan, G. (2015). Words Jump-Start Vision: A Label Advantage in Object Recognition. The Journal of Neuroscience, 35(25), 9329-9335.

Bull, R., \& Scerif, G. (2001). Executive functioning as a predictor of children's mathematics ability: Inhibition, switching, and working memory. Developmental Neuropsychology, 19(3), 273-293. 
Buchsbaum, B. R., Greer, S., Chang, W. L., \& Berman, K. F. (2005). Meta-analysis of neuroimaging studies of the Wisconsin card-sorting task and component processes. Human Brain Mapping, 25(1), 35-45.

Calvo, A., \& Bialystok, E. (2014). Independent effects of bilingualism and socioeconomic status on language ability and executive functioning. Cognition, 130(3), 278-288.

Carlesimo, G. A., Fadda, L., Lorusso, S., \& Caltagirone, C. (1994). Verbal and spatial memory spans in Alzheimer's and multi-infarct dementia. Acta Neurologica Scandinavica, 89(2), 132-138.

Carlson, S. M., Moses, L. J., \& Claxton, L. J. (2004). Individual differences in executive functioning and theory of mind: An investigation of inhibitory control and planning ability. Journal of Experimental Child Psychology, 87(4), 299-319.

Casasola, M., \& Bhagwat, J. (2007). Do Novel Words Facilitate 18-Month-Olds' Spatial Categorization? Child Development, 78(6), 1818-1829.

Cenoz, J. (2003). The additive effect of bilingualism on third language acquisition: a review. International Journal of Bilingualism, 7(1), 71-87.

Cenoz, J., and Valencia, J. F. (1994). Additive trilingualism: evidence from the Basque country. Applied Psycholinguistics, 15(02), 195-207.

Chey, J., Lee, J., Kim, Y. S., Kwon, S. M., \& Shin, Y. M. (2002). Spatial working memory span, delayed response and executive function in schizophrenia. Psychiatry Research, 110(3), 259-271.

Daneman, M., \& Carpenter, P. A. (1980). Individual differences in working memory and reading. Journal of Verbal Learning and Verbal Behavior, 19(4), 450-466.

Davidson, D., Jergovic, D., Imami, Z., \& Theodos, V. (1997). Monolingual and bilingual children's use of the mutual exclusivity constraint. Journal of Child Language, 24(01), 3-24.

Davidson, N. S., \& Gelman, S. A. (1990). Inductions from novel categories: The role of language and conceptual structure. Cognitive Development, 5(2), 151-176.

De Abreu, P. M. J. E., Gathercole, S. E., \& Martin, R. (2011). Disentangling the relationship between working memory and language: The roles of short-term storage and cognitive control. Learning and Individual Differences, 21(5), 569574. 
Dehaene, S., Artiges, E., Naccache, L., Martelli, C., Viard, A., Schürhoff, F., Recasens, C., Palliere Martinot, M. L., Leboyer, M., \& Martinot, J. L. (2003). Conscious and subliminal conflicts in normal subjects and patients with schizophrenia: the role of the anterior cingulate. Proceedings of the National Academy of Sciences, 100(23), 13722-13727.

Deng, W., \& Sloutsky, V. M. (2012). Carrot-eaters and moving heads: Salient features provide greater support for inductive inference than category labels.

Psychological Science, 23(2), 178-186.

Dessalegn, B., \& Landau, B. (2013). Interaction between language and vision: It's momentary, abstract, and it develops. Cognition, 127(3), 331-344.

Diamond, A. (2013). Executive functions. Annual Review of Psychology, 64, 135.

Diesendruck, G., \& Peretz, S. (2013). Domain differences in the weights of perceptual and conceptual information in children's categorization. Developmental Psychology, 49(12), 2383-2395.

Eriksen, B. A., \& Eriksen, C. W. (1974). Effects of noise letters upon the identification of a target letter in a nonsearch task. Perception \& Psychophysics, 16(1), 143-149.

Ferguson, B., Havy, M., \& Waxman, S. R. (2015). The precision of 12-month-old infants' link between language and categorization predicts vocabulary size at 12 and 18 months. Frontiers in Psychology, 6(1319), 1-6.

Ferry, A. L., Hespos, S. J., \& Waxman, S. R. (2010). Categorization in 3- and 4month-old infants: an advantage of words over tones. Child Development, 81(2), 472-9.

Ferry, A. L., Hespos, S. J., \& Waxman, S. R. (2013). Nonhuman primate vocalizations support categorization in very young human infants. Proceedings of the National Academy of Sciences of the United States of America, 110(38), $15231-15235$.

Fischer, M. H. (2001). Probing spatial working memory with the Corsi blocks task. Brain and Cognition, 45(2), 143-154.

Fulkerson, A. L., \& Waxman, S. R. (2007). Words (but not tones) facilitate object categorization: Evidence from 6-and 12-month-olds. Cognition, 105(1), 218228. 
Gelman, S. A., \& Coley, J. D. (1990). The importance of knowing a dodo is a bird: Categories and inferences in 2-year-old children. Developmental Psychology, 26(5), 796-804.

Gelman, S. A., \& Davidson, N. S. (2013). Conceptual influences on category-based induction. Cognitive Psychology, 66(3), 327-353.

Gelman, S. A., \& Markman, E. M. (1986). Categories and induction in young children. Cognition, 23(3), 183-209.

Gelman, S. A., \& Markman, E. M. (1987). Young children's inductions from natural kinds: The role of categories and appearances. Child Development, 58(6), $1532-1541$.

Gelman, S. A., \& O'Reilly, A. W. (1988). Children's inductive inferences within superordinate categories: The role of language and category structure. Child Development, 59(4), 876-887.

Gelman, S. A. (2013). Artifacts and essentialism. Review of Philosophy and Psychology, 4(3), 449-463.

Gershkoff-Stowe, L., \& Smith, L. B. (2004). Shape and the first hundred nouns. Child Development, 75(4), 1098-1114.

Gervits, F., Johanson, M., \& Papafragou, A. (2016). Intentionality and the role of labels in categorization. Proceedings from the $38^{\text {th }}$ Annual Meeting of the Cognitive Science Society, 1146-1151.

Gold, J. M., Carpenter, C., Randolph, C., Goldberg, T. E., \& Weinberger, D. R. (1997). Auditory working memory and Wisconsin Card Sorting Test performance in schizophrenia. Archives of General Psychiatry, 54(2), 159-165.

Goldstone, R. L., Lippa, Y., \& Shiffrin, R. M. (2001). Altering object representations through category learning. Cognition, 78(1), 27-43.

Grosjean, F. (1989). Neurolinguists, beware! The bilingual is not two monolinguals in one person. Brain and Language, 36(1), 3-15.

Hahne, A., \& Friederici, A. D. (2001). Processing a second language: Late learners' comprehension mechanisms as revealed by event-related brain potentials. Bilingualism: Language and Cognition, 4(02), 123-141.

Harrington, M. (2006). The lexical decision task as a measure of L2 lexical proficiency. EUROSLA Yearbook, 6(1), 147-168. 
Hermans, D., Bongaerts, T., De Bot, K., \& Schreuder, R. (1998). Producing words in a foreign language: Can speakers prevent interference from their first language? Bilingualism: Language and Cognition, 1(3), 213-229.

Johanson, M., \& Papafragou, A. (2016). The influence of labels and facts on children's and adults' categorization. Journal of Experimental Child Psychology, 144, 130-151.

Jones, S. S., Smith, L. B., \& Landau, B. (1991). Object properties and knowledge in early lexical learning. Child Development, 62(3), 499-516.

Kane, M. J., \& Engle, R. W. (2002). The role of prefrontal cortex in working-memory capacity, executive attention, and general fluid intelligence: An individualdifferences perspective. Psychonomic Bulletin \& Review, 9(4), 637-671.

Kaushanskaya, M., \& Marian, V. (2009). The bilingual advantage in novel word learning. Psychonomic Bulletin \& Review, 16(4), 705-710.

Keshavarz, M. H., and Astaneh, H. (2004). The impact of bilinguality on the learning of English vocabulary as a foreign language (L3). International Journal of Bilingual Education and Bilingualism, 7(4), 295-302.

Kessels, R. P., Van Zandvoort, M. J., Postma, A., Kappelle, L. J., \& De Haan, E. H. (2000). The Corsi block-tapping task: standardization and normative data. Applied Neuropsychology, 7(4), 252-258.

Kongs, S. K., Thompson, L. L., Iverson, G. L., \& Heaton, R. K. (2000). Wisconsin card sorting test-64 card version (WCST-64). Odessa, FL: Psychological Assessment Resources.

Kroll, J. F., Bobb, S. C., Misra, M., \& Guo, T. (2008). Language selection in bilingual speech: Evidence for inhibitory processes. Acta Psychologica, 128(3), 416430.

Landau, B., \& Shipley, E. (2001). Labelling patterns and object naming. Developmental Science, 4(1), 109-118.

Lupyan, G., \& Thompson-Schill, S. L. (2012). The evocative power of words: activation of concepts by verbal and nonverbal means. Journal of Experimental Psychology: General, 141(1), 170.

Lupyan, G., Rakison, D. H., \& McClelland, J. L. (2007). Language is not just for talking redundant labels facilitate learning of novel categories. Psychological Science, 18(12), 1077-1083. 
Mathôt, S., Schreij, D., \& Theeuwes, J. (2012). OpenSesame: An open-source, graphical experiment builder for the social sciences. Behavior Research Methods, 44(2), 314-324.

Miyake, A., \& Friedman, N. P. (2012). The nature and organization of individual differences in executive functions four general conclusions. Current Directions in Psychological Science, 21(1), 8-14.

Mueller, S. T. \& Piper, B. J. (2014). The Psychology Experiment Building Language (PEBL) and PEBL Test Battery. Journal of Neuroscience Methods, 222, 250259.

Nazzi, T., \& Gopnik, A. (2001). Linguistic and cognitive abilities in infancy: when does language become a tool for categorization? Cognition, 80(3), B11-B20.

Oakes, L. M., \& Rakison, D. H. (2003). Issues in the early development of concepts and categories: An introduction. In L. M. Oakes \& Rakison, D. H. (Eds.), Early category and concept development: Making sense of the blooming, buzzing confusion (pp. 3-23). New York, NY: Oxford University Press.

Pavlenko, A., \& Malt, B. C. (2011). Kitchen Russian: Cross-linguistic differences and first-language object naming by Russian-English bilinguals. Bilingualism: Language and Cognition, 14(01), 19-45.

Plunkett, K., Hu, J. F., \& Cohen, L. B. (2008). Labels can override perceptual categories in early infancy. Cognition, 106(2), 665-681.

Rastle, K., Harrington, J., \& Coltheart, M. (2002). 358,534 nonwords: The ARC Nonword Database. Quarterly Journal of Experimental Psychology, 55A, 1339-1362.

Rhodes, M., \& Gelman, S. A. (2009). Five-year-olds' beliefs about the discreteness of category boundaries for animals and artifacts. Psychonomic Bulletin \& Review, 16(5), 920-924.

Rhodes, M. G. (2004). Age-related differences in performance on the Wisconsin card sorting test: a meta-analytic review. Psychology and Aging, 19(3), 482-494.

Romine, C. B., Lee, D., Wolfe, M. E., Homack, S., George, C., \& Riccio, C. A. (2004). Wisconsin Card Sorting Test with children: a meta-analytic study of sensitivity and specificity. Archives of Clinical Neuropsychology, 19(8), 10271041. 
Sanz, C. (2000). Bilingual education enhances third language acquisition: evidence from Catalonia. Applied Psycholinguistics, 21(01), 23-44.

Shuell, T. J., \& Giglio, J. (1973). Learning ability and short-term memory. Journal of Educational Psychology, 64(3), 261-266.

Shulman, H. G., \& Greenberg, S. N. (1971). Perceptual deficit due to division of attention between memory and perception. Journal of Experimental Psychology, 88(2), 171-176.

Sloutsky, V. M., \& Fisher, A. V. (2012). Linguistic labels: conceptual markers or object features? Journal of Experimental Child Psychology, 111(1), 65-86.

Sloutsky, V. M., Kloos, H., \& Fisher, A. V. (2007). When looks are everything Appearance similarity versus kind information in early induction. Psychological Science, 18(2), 179-185.

Sloutsky, V. M., Lo, Y. F., \& Fisher, A. V. (2001). How much does a shared name make things similar? Linguistic labels, similarity, and the development of inductive inference. Child Development, 72(6), 1695-1709.

Smith, L. B., Jones, S. S., \& Landau, B. (1996). Naming in young children: A dumb attentional mechanism? Cognition, 60(2), 143-171.

Stoffers, D., Berendse, H. W., Deijen, J. B., \& Wolters, E. C. (2003). Deficits on Corsi's block-tapping task in early stage Parkinson's disease. Parkinsonism \& Related Disorders, 10(2), 107-111.

Stuss, D.T., Levine, B., Alexander, M.P., Hong, J., Palumbo, C., Hamer, L., Murphy, K.J. and Izukawa, D. (2000). Wisconsin Card Sorting Test performance in patients with focal frontal and posterior brain damage: Effects of lesion location and test structure on separable cognitive processes. Neuropsychologia, 38(4), 388-402.

Tanner, D., \& Van Hell, J. G. (2014). ERPs reveal individual differences in morphosyntactic processing. Neuropsychologia, 56, 289-301.

Tanner, D., Inoue, K., \& Osterhout, L. (2014). Brain-based individual differences in online L2 grammatical comprehension. Bilingualism: Language and Cognition, 17(02), 277-293.

Van Hell, J. G., \& Dijkstra, T. (2002). Foreign language knowledge can influence native language performance in exclusively native contexts. Psychonomic Bulletin \& Review, 9(4), 780-789. 
Van Hell, J. G., and Mahn, A. C. (1997). Keyword mnemonics versus rote rehearsal: learning concrete and abstract foreign words by experienced and inexperienced learners. Language Learning, 47(3), 507-546.

Vidal, J. R., Perrone-Bertolotti, M., Levy, J., De Palma, L., Minotti, L., Kahane, P., Bertrand, O., Lutz, A., Jerbi, K., \& Lachaux, J. P. (2014). Neural repetition suppression in ventral occipito-temporal cortex occurs during conscious and unconscious processing of frequent stimuli. Neuroimage, 95, 129-135.

Waxman S. R., \& Markow, D. B. (1995). Words as invitations to form categories: Evidence from 12-to 13-month-old infants. Cognitive Psychology, 29(3), 257302.

Waxman, S. R. (1999). Specifying the scope of 13-month-olds' expectations for novel words. Cognition, 70(3), B35-B50.

Welder, A. N., \& Graham, S. A. (2006). Infants' categorization of novel objects with more or less obvious features. Cognitive Psychology, 52(1), 57-91.

Wolff, P., \& Holmes, K. J. (2011). Linguistic relativity. Wiley Interdisciplinary Reviews: Cognitive Science, 2(3), 253-265.

Wöstmann, N. M., Aichert, D. S., Costa, A., Rubia, K., Möller, H. J., \& Ettinger, U. (2013). Reliability and plasticity of response inhibition and interference control. Brain and Cognition, 81(1), 82-94.

Yamauchi, T., \& Markman, A. B. (2000). Inference using categories. Journal of Experimental Psychology: Learning, Memory, and Cognition, 26(3), 776.

Zelazo, P. D. (2006). The Dimensional Change Card Sort (DCCS): A method of assessing executive function in children. Nature Protocols, 1(1), 297-301. 
Appendix

INSTITUTIONAL REVIEW BOARD APPROVAL 


\section{๑}

\section{Research Office}

210 Hullihen Hall

University of Delaware

Newark, Delaware 19716-1551

Ph: 302/831-2136

Fax: 302/831-2828

DATE:

March 3, 2017

TO:

FROM:

Anna Papafragou, $\mathrm{PhD}$

University of Delaware IRB

STUDY TITLE:

[312739-16] Language Acquisition: Word learning and pragmatic inference

IRB REFERENCE \#:

SUBMISSION TYPE:

Continuing Review/Progress Report

ACTION:

APPROVED

APPROVAL DATE:

March 3, 2017

EXPIRATION DATE:

March 1, 2018

REVIEW TYPE:

Expedited Review

REVIEW CATEGORY: Expedited review category \# (7)

Thank you for your submission of Continuing Review/Progress Report materials for this research study. The University of Delaware IRB has APPROVED your submission. This approval is based on an appropriate risk/benefit ratio and a study design wherein the risks have been minimized. All research must be conducted in accordance with this approved submission.

This submission has received Expedited Review based on the applicable federal regulation.

Please remember that informed consent is a process beginning with a description of the study and insurance of participant understanding followed by a signed consent form. Informed consent must continue throughout the study via a dialogue between the researcher and research participant. Federal regulations require each participant receive a copy of the signed consent document.

Please note that any revision to previously approved materials must be approved by this office prior to initiation. Please use the appropriate revision forms for this procedure.

All SERIOUS and UNEXPECTED adverse events must be reported to this office. Please use the appropriate adverse event forms for this procedure. All sponsor reporting requirements should also be followed.

Please report all NON-COMPLIANCE issues or COMPLAINTS regarding this study to this office.

Please note that all research records must be retained for a minimum of three years.

Based on the risks, this project requires Continuing Review by this office on an annual basis. Please use the appropriate renewal forms for this procedure. 
If you have any questions, please contact Nicole Farnese-McFarlane at (302) 831-1119 or nicolefm@udel.edu. Please include your study title and reference number in all correspondence with this office. 